\title{
PAI: SEU LUGAR NA ESPERA DO NASCIMENTO DO(A) FILHO(A) ${ }^{1}$
}

\author{
FATHER: HIS PLACE WHILE WATING HIS CHILDREN'S BIRTH \\ PADRE: SU LUGAR EN LA ESPERA DEL NACIMIENTO \\ DEL(DELA) HIJO(A)
}

Daniela de Oliveira Paula²

RESUMO: Esse trabalho é escrito com o intuito de identificar o lugar onde o pai encontra-se no momento do nascimento de seu(a) filho(a) e suas percepçōes quanto a este lugar. Trata-se de um estudo de natureza qualitativa, que utiliza o referencial de Minayo (1996) de análise do discurso. Para tanto, sāo entrevistados 23 pais cujos(as) filhos(as) nasceram a menos de um ano, sendo abordados diretamente e entrevistados em locais de circulação pública. Verifica-se que apenas sete pais estiveram presentes no momento da parturição de seus(as) filhos(as), sendo que, somente um destes teve o parto da mulher atendido pelo SUS. Os demais entrevistados estiveram ausentes do local de nascimento do(a) filho(a). Conclui-se que apesar da bibliografia incentivar sua presença no momento do nascimento para interação precoce pai-bebê, na prática encontra-se uma realidade onde, principalmente em hospitais que atendem pelo SUS, os homens são excluidos deste momento tāo importante.

PALAVRAS-CHAVE: pai, lugar de espera, percepçōes do pai, repercussões, SUS.

\section{A VIVÊNCIA}

Em nossa sociedade, na maioria das vezes, o homem tem pouca ou nenhuma participação nos eventos ligados ao nascimento. Poucos săo os homens que podem ou querem participar dos eventos relacionados ao nascimento como consultas de pré-natal, cursos ou palestras de preparação para o parto e, menos ainda, são aqueles que assistem o parto. Não será simplesmente assistindo o trabalho de parto e parto que o homem vai estar contribuindo para um melhor desenvolvimento de seu bebê. Assim, para um melhor entendimento das tensōes e dificuldades que podem ser encontradas, os mesmos devem ser informados sobre tudo o que está acontecendo, pois "quanto mais bem preparado estiver o pai, mais apoio pode oferecer" (Knuppel \& Drukker, 1996, p.577). A realidade dos Centros Obstétricos de nossos hospitais, principalmente os públicos, encontra-se uma grande resistência dos profissionais da área em liberarem a entrada do pai na sala de parto.

Enquanto a mulher sente-se e é considerada mãe desde o momento em que recebe a noticia da gravidez, para o homem este momento só se consagra após o nascimento de seu(a) filho(a). A paternidade é um processo que vai sendo construido aos poucos, a medida que o homem assume suas responsabilidades e vinculos com o(a) filho(a). Para Mello (1999, p. 54) o(a) filho(a) é o espelho das realizações do pai e a resolução de suas frustraçōes, "mais do que uma obrigação, faz parte da realizaçăo plena de sua masculinidade".

Ao longo da gestação, o bebê encontra-se durante nove meses em contato com o

'Trabalho realizado sob orientação da Prof. ${ }^{a}$ Mestre Mariene Jaeger Riffel, na Disciplina "Estágio Curricular"/ $9^{\circ}$ Semestre.

${ }^{2}$ Formanda do curso de Enfermagem da Universidade Federal do Rio Grande do Sul. 
corpo da mãe. Rohde (1991) demonstra que os bebês, mesmo antes do nascimento, já estão capacitados para o inicio do desenvolvimento de um vinculo com os pais, porém, para

Schneider (1997, p. 113), "o papel do pai no momento do parto e pré-parto é um assunto pouco pesquisado".

Sabe-se que a interação precoce pai-bebê mostra um melhor envolvimento posterior destes podendo interferir, segundo Rohde (1991) no relacionamento conjugal do casal, fazendo com que o pai sinta-se com mais poder e condiçōes para desenvolver uma boa interação com o filho e, tornando a mãe, com suas atitudes, mais competente para a amamentação, servindo de sustentáculo para esta interagir bem com o bebê, abrindo caminho para novas conquistas da criança.

Prado $(1999, p .5)$ afirma que a determinação da paternidade inicia-se desde a decisão do casal em ter seu filho, abrangendo a gestação e as primeiras semanas de vida do bebê. Neste periodo, o pai tem um importante papel de organizar o "ninho" para a vinda da criança e dar suporte afetivo à mãe. A ausência do pai neste periodo pode acarretar problemas que atingem indiretamente a criança, como falhas na organização do núcleo familiar e estados de insatisfação e depressão afetiva na mãe. Ainda conforme o autor, "mães que têm seu filho sem a presença do pai (neste periodo), seja por que razões forem, sempre sofrem profundamente, ficando prejudicadas suas melhores condições para o desenvolvimento da função materna".

No decorrer de minhas atividades na Unidade de Centro Obstétrico do Hospital de Clínicas de Porto Alegre, por ocasião do Estágio Curricular, cursado no último semestre do curso de graduação em enfermagem, observo diversos aspectos que chamam atenção, mas o principal, o que me intriga, é a ausência do pai junto à mulher no trabalho de parto e parto. Diante deste meu estranhamento e a partir da leitura de Espirito Santo (1993) "Sentimentos e percepçōes do pai quanto a sua presença na sala de parto" decido realizar este trabalho investigativo.

\section{OS OBJETIVOS}

A partir das colocaçōes anteriores, decido desenvolver minha monografia investigando pais cujos(as) filhos(as) nasceram a menos de um ano. Para isto, são elaborados os seguintes objetivos:

- identificar onde estavam os pais no momento do nascimento de seu(a) filho(a);

- conhecer a percepção do pai quanto à adequação do lugar de espera do nascimento do(a) filho(a).

\section{METODOLOGIA}

O estudo, de natureza qualitativa, não trata de situações quantificáveis. A condição básica de Mynaio (1997) para a pesquisa qualitativa não se baseia no critério numérico para garantir sua representatividade: a amostragem boa é aquela que possibilita abranger a totalidade do problema investigado em suas múltiplas dimensões.

Assim, a pesquisa é realizada a partir das informações fornecidas por 23 pais, escolhidos aleatoriamente, através da abordagem direta de homens acompanhados de crianças com menos de um ano de idade em locais de circulaçăo pública. O periodo de menos de um ano de idade das crianças é escolhido como critério para que se pudesse obter dados de experiências recentes.

A pesquisa é desenvolvida no periodo de abril a julho de 1999.

$\mathrm{Na}$ coleta de dados utiliza-se "guia de tópicos" para "entrevistas com um foco", contendo perguntas "fechadas" $\mathrm{e}$ "aberto-fechadas" sobre onde encontrava-se o pai no momento nascimento de seu(a) filho(a) e sua percepção quanto a este local. Contempla-se, então, uma das prerrogativas 
de Polit (1995, p.168) ao valorizar o respondente no momento em que permite-se "aos sujeitos responderem com suas próprias palavras".

Outro instrumento utilizado é o "consentimento autorizado", verbal e prévio dos entrevistados. A entrevista só é realizada após esta confirmaçăo.

Para manter o sigilo sobre a identidade dos respondentes, são utilizados números para sua identificação (p. ex.: pai 9). Assim, contempla-se a necessidade dos sujeitos de informaçăo adequada e preservação do anonimato (Polit, 1995).

Para garantir a fidedignidade das informações, as entrevistas são anotadas e logo após transcritas pela autora com ajuda de um computador, obtendo melhor vizualização e rapidez no tratamento destas.

Como suporte metodológico para análise, utiliza-se o referencial teórico de Minayo (1996), que propōe os seguintes passos para operacionalização:

- Observação dos dados: engloba as entrevistas

- Classificaçăo dos dados: feita em duas etapas:

- primeira: leitura exaustiva e repetida dos textos, apreendendo idéias centrais que os respondentes tentam transmitir sobre o tema proposto;

- segunda: constituição de vários "corpus" de comunicação, pois trata-se de informações não homogêneas.

- Destacamento em unidades de registro: as entrevistas são referenciadas por tópicos de informação, cujos temas são classificados de acordo com sua relevância.

O conjunto do material passa pela análise do discurso, com o objetivo básico de gerar reflexão sobre o tema proposto.

\section{ANÁLISE E INTERPRETAÇÃO DOS DADOS}

Após entrevistar 23 pais, as informaçōes começam a tornar-se repetitivas.

Encontra-se 16 pais cujos partos são custeados pelo SUS e 7 pais cujos partos são custeados por convênios ou privativamente.

Constata-se que 16 dos 23 pais não estiveram presentes na sala de parto por ocasião do nascimento de seu(a) filho(a) e, portanto, apenas sete assistiram ao parto.

Seis dos sete nascimentos que ocorrem por convênio ou particular têm a presença dos pais por vontade própria na sala de parto. $O$ único pai deste grupo que não permaneceu junto à mulher, neste momento, o fez por solicitação da mesma.

O único pai cujo parto é custeado pelo SUS, e que assistiu o nascimento de seu filho, acompanhava a gestante na sala de trabalho de parto, quando ocorre o nascimento não previsto para aquele momento ou lugar.

Dos pais cujos partos dos filhos(as) ocorreram pelo SUS, cinco encontravam-se no corredor do hospital, quatro na sala de espera, dois no lado de fora do hospital, dois em suas casas e dois no local de trabalho, na ocasiăo do nascimento.

Existem vários motivos que determinam a permanência dos pais em locais diversos, no momento do nascimento de seus(as) filhos(as). Doze, dos 23 pais, não permanecem com suas esposas em sala de parto pois as instituiçōes não permitem. Todos os hospitais que não consentiram na presença do pai junto a mulher durante o momento da parturição são hospitais públicos. O motivo referido pelos outros quatro pais são: dois encontravam-se no trabalho e não foram avisados à tempo; um cedeu seu lugar para a mãe da esposa e o quarto encontrava-se em seu domicilio pois a esposa estava internada há vários dias.

$\mathrm{Na}$ análise das informaçōes fica evidente a formaçāo de três "corpus": pais presentes 
no local do nascimento do(a) filho (a), pais ausentes no local do evento e o pai como fator de segurança e apoio.

\section{PAIS PRESENTES NO LOCAL DO NASCIMENTO DO(A) FILHO (A)}

Na conferência patrocinada pela Organização Mundial da Saúde - OMS (1985), na cidade de Fortaleza - CE, foram revisadas as Tecnologias Apropriadas para o Nascimento. A primeira tecnologia recomendada refere-se ao reconhecimento do valor emocional do acompanhante $e$ preconiza

"o bem estar da futura mãe deve ser assegurado através do livre acesso de um acompanhante, por ela escolhido, ao parto e puerpério. Além disso, a equipe de saúde deve proporcionar-Ihe apoio emocional" (OMS, 1985).

Assim, uma das situaçōes que chama a atenção na análise, é a presença de menos de um terço dos pais entrevistados no local do nascimento do(a) filho(a), além do fato de, apenas um pai, cujo filho nasce em maternidade conveniada pelo SUS, tem a oportunidade de estar presente na ocasião do nascimento demonstrando claramente, as dificuldades dos profissionais da saúde destes serviços em adequarem-se a primeira tecnologia preconizada. Salienta-se que esta situação foi proporcionada puramente pelo acaso, como nos relata o próprio pai.

...eu estava acompanhando minha esposa. Ela estava com as dores e eu fiquei com ela. Os médicos entravam às vezes para ver como ela estava, mas teve uma hora que ela chamou e eles demoraram para vir, quando chegaram o nenê estava nascendo e o parto foi no quarto (Pai 11).

Mesmo sendo uma experiência inesperada, este pai refere-a como tendo sido "uma experiência ótima" apesar de não sentir-se "muito preparado". Quando falamos no preparo do pai para participar do momento do parto, podemos pensar que a mãe, mesmo não participando de cursos, palestras, realizando leituras ou até não freqüentando consultas de pré-natal, não é "impedida" de parir, e assim, pergunta-se: porque é cobrado do pai a participaçăo em tais eventos como condição indispensável, para que esteja presente no local do nascimento de seu(a) filho(a)?

Conforme Rohde (1991) um dos aspectos importantes quanto ao pai que está presente na sala de parto é a exaltação, a alegria e capacidade deste em diferenciar seu bebê de outros recém-nascidos demonstradas por alguns.

Foi maravilhoso, muito bom. Foi o dia mais feliz em minha vida. $E$ bom ver o filho nascer e incentivar a esposa nesta hora (Pai 2).

Foi emocionante estar dentro da sala e ser o primeiro a ver o nenê. Vale a pena, quem não participa se arrepende (Pai 6).

Schneider (1997) afirma que a paternidade traz mudanças na visão de mundo, no jeito de amar e nas preocupaçōes na vida dos sujeitos. A possibilidade de refletir sobre a fragilidade de nossa espécie expressa-se em falas como a do pai que segue:

Foi ótimo. Maravilhoso. Fiquei emocionado e até chorei (Pai 16).

Raphael-Leff (1997, p. 62) salienta que "o nascimento realça a diferença fundamental entre os sexos como nenhuma outra situação pode fazê-lo". Desta maneira, a possibilidade encontrada, por alguns pais, de inclusão no processo de nascimento é, também, permanecer no local do parto com a mulher. Para Ziegel (1985), o contato nos primeiros minutos e horas de vida mãe-filho e pai-filho são importantes para o desenvolvimento afetivo ulterior da familia.

Era o único lugar que eu deveria estar nesta hora, dando força para ela (Pai 3).

O parto sempre envolve a possibilidade de eventos inesperados. Quando o pai não tem informaçōes adequadas ou suficientes, pode sentir uma ansiedade aumentada em relação ao momento. Desta maneira, salienta-se como adequados os sentimentos evidenciados pelo pai 3 , visto que estes sentimentos são conseqúentes à alegria referida. 
Foi uma experiência nova, alegre, diferente. Me senti ansioso, nervoso (Pai 3).

Para muitos homens năo basta simplesmente a vontade de assistir o parto. Mais do que passar pela burocracia do hospital e conseguir a permissão para sua permanência no local do nascimento do(a) filho (a), é necessário ultrapassar uma barreira ainda maior - entrar em contato com a visão da cena "ensangüentada" do parto. A presença de sangue e a percepção de impotência sentida pelo homem em face à dor e às intensas exigências emocionais que a situação provoca na mulher, fazem emergir ansiedades masculinas traduzidas em "Poderosas paixőes, da qual está fisicamente excluido, enquanto emocionalmente envolvido" (RaphaelLeff, 1997, p. 63). Este quadro pode ser exemplificado pelo sentimento expresso pelo pai que segue.

Assistir o nascimento de meu filho foi uma experiência ótima, mas eu não estava muito preparado e na hora me deu vontade de sair correndo do quarto (Pai 11).

Fiquei ansioso, não sei se entraria, não gosto de sangue, mas ficar fora é horrivel, não se sabe o que tá acontecendo, se vai demorar, se tá tudo bem (Pai 18).

Me senti impotente, queria ajudar minha mulher e ver meu filho, mas eles me pediram para sair quando ela ia para a sala de parto (Pai 22).

Para Raphael-Leff (1997) nos dias de hoje, ainda convivemos em uma sociedade onde os homens sentem-se deslocados na ocasião do parto e pré-parto, alegando que este é um momento de mulheres. Alguns ainda tem a visão do nascimento dos irmãos, onde o pai andava de um lado para outro na sala e a parteira e suas ajudantes subiam com bacias de água quente e toalhas e estes só eram chamados após o nascimento do(a) filho(a).

Porém, a realidade dos homens entrevistados, que assistiram o parto de seu(a) filho(a), nos revela que este é um momento único, emocionante e, imprescindivel para o bem estar da criança e da mulher.

\section{PAIS AUSENTES DO LOCAL DO NASCIMENTO DO(A) FILHO (A)}

Ainda hoje, as rotinas das grandes maternidades não incluem a presença do pai, seja no trabalho de parto e menos ainda no momento da parturição. Porém, em paises desenvolvidos, quase todos os homens participam do nascimento de seus(as) filhos(as) e, participar já faz parte da cultura popular, assim como a interaçäo precoce pai-bebê, modificando, inclusive as rotinas pós-parto. As visitas, antes restritas ao contato com o filho através do vidro do berçário, tornam-se visitas irrestritas, e o contato mais intenso deste com a mulher e com o recémnascido passa a ser estimulado com a intenção de propiciar à criança um melhor desenvolvimento cognitivo e, aos pais, laços de apego (Rohde, 1991).

Neste trabalho constata-se que, apesar do interesse de raros profissionais e parte da populaçăo quanto a presença de familiar, há uma passividade e conformismo com o fato de não ser permitida sua entrada na maior parte das instituições onde ocorrem os nascimentos.

Durante os dois meses de permanência em campo de estágio, não presencio a entrada de nenhum pai junto à esposa no momento do parto. Esta dicotomia entre a bibliografia e a realidade chama-me atenção: a exclusão do pai pela equipe médica, que afirma não gostar da presença do pai, "pois o mesmo atrapalha". Mesmo durante o trabalho de parto, poucos homens permanecem com suas esposas. Em algumas situações, o lugar é cedido à măe da gestante e, muitas vezes, a gestante permanece sem acompanhante. É o que acontece com um dos pais entrevistados, cuja fala, é a seguir relatada:

Eu estava em casa quando meu filho nasceu. ...o trabalho de parto estava demorado e eu decidi ir para casa, a mãe dela ficou no hospital. ... Fiquei vendo TV, tentando me distrair, mas toda hora eu me lembrava dela (Pai 4). 
Rodhe (1991, p. 87) cita que "O nascimento de um filho, ou seja, o surgimento de um terceiro na relação exclusiva marido-mulher, corresponde ao ingresso do pai na relação exclusiva mãe-bebê". Esta inclusão é, geralmente dificultada nas instituições hospitalares de nossa cidade, por ocasião da exclusão do pai do local do nascimento do(a) filho(a). Alguns demonstram este sentimento através de falas que indicam uma preocupação excessiva com a esposa:

Fiquei aflito. Preocupava-me com minha esposa e o nenê. Queria que tudo desse certo. Foi ruim não estar com ela no momento do nascimento (Pai 13).

A paternidade pode gerar sentimentos ambivalentes quando o pai é afastado do trabalho de parto e/ou do momento do parto, ou mesmo quando este participa dos acontecimentos, segundo Costa ; Katz (1992). Em pesquisa sobre paternidade citada por este autor, entre dez pais entrevistados imediatamente após o nascimento do primeiro filho, sete referiram terem experimentado temores que a mulher morresse e, três deles, que o recém-nascido morresse durante o parto.

... o parto complicou os médicos me mandaram sair. Eu estava com muito medo que meu filho morresse. Ninguém me dava explicação e o tempo não passava. Foram momentos de angústia. Espero que isto nunca mais aconteça (Pai 10).

Não há necessidade nem razão para privar a mulher do apoio emocional e assistência amorosa do marido. Mas em nossa realidade o lugar do homem é, excepcionalmente, ao lado da mulher na cabeceira da cama enquanto em trabalho de parto. Na maioria das vezes sua presença acalma e dá segurança a mulher. Um dos pais respondentes revela seus sentimentos frente a sua exclusão do momento do parto:

Eu me senti inseguro estando longe de minha esposa. Acho que o marido devia estar ao lado da mulher dando apoio nesta hora, fazendo força junto (Pai 14).

As questões relativas a manutenção da familia e ao sustento da casa ainda estão associadas prioritariamente ao homem, fazendo com que muitas vezes este esteja trabalhando por ocasião do nascimento de seu(a) filho(a). A comunicação da ocorrência do nascimento iminente faz-se geralmente em tempo não hábil. Com isto, muitos pais estão ausentes do processo da parturição uma vez que a familia, presente à instituição, também tem poucas informaçōes e só as transmite ao pai após o nascimento do(a) filho (a). É o que ocorre com o pai que segue:

...minha esposa estava na casa da mãe e só me chamaram quando o nenê nasceu. Foi frustrante. Eu nada sabia. Foi uma surpresa. Quando fui ao hospital me mostraram a nenê e disseram que minha esposa passava bem (Pai 9).

O parto não escolhe momento para ocorrer. Assim, o lugar de espera do pai no nascimento de seu(a) filho(a) pode ser o trajeto até a maternidade, como relata o Pai 17 (estava no trabalho) e o Pai 19 (aguardava o horário da visita em casa).

...minha mulher entrou em trabalho de parto e foi para o hospital. De lá me ligaram avisando que ela tinha baixado para ganhar o nenê. Quando recebi a noticia, fiquei nervoso e corri para chegar na hora no hospital, mas não consegui ...só pude vê-la duas horas depois que nasceu o nenê (Pai 17).

... minha mulher estava internada no hospital há dias e eu visitava ela. Mas neste dia eu não fui e o nenê nasceu. ...foi uma surpresa (Pai 19).

No momento do nascimento de um filho o sentimento de angústia intensa pode tomar conta do pai. Segundo Costa; Katz (1992, p. 76) este fato é mostrado "em quadros humorísticos por pais aflitos caminhando em círculos e fumando vários cigarros numa sala de espera da maternidade" . No depoimento do pai, a seguir, pode-se "visualizar" situação semelhante à descrita por este autor.

Me senti angustiado. Queria saber como estava minha esposa e minha filha. Foram momentos intermináveis, até vir uma pessoa e chamar pelo familiar. Quando disse que elas estavam bem, me senti um pouco melhor (Pai 7). 
Algumas mulheres tomam a decisão de excluirem seus parceiros do momento do parto. Muitas por receio que este não compreenda os acontecimentos fisiológicos e anatômicos que estão por vir. Nestes casos é preciso respeitar a vontade da mãe, embora segundo RaphaelLeff (1997, p. 63) é necessário considerar, também, a decisão masculina. $\quad \mathrm{M}$ in h a opinião é que uma decisão consciente, pensada em conjunto pelo casal, pode evitar lamentações pela ausência do pai no momento da parturição e a compreensão tardia do que poderia ter sido feito.

O Pai 18 , único cuja mulher não quis que o marido entrasse em sala de parto, teve a sala de espera do hospital, como local de aguardo do nascimento de seu filho.

...minha esposa não quis que eu entrasse na sala de parto. Os médicos deixavam entrar, mas ela não quis (Pai 18).

A intimidade entre pai e filho é construida na medida em que relação de amor e carinho se estabelece. Mello (1999), afirma que quando há desinteresse ou ausência do pai, os prejuizos ao desenvolvimento da criança refletem-se em aspectos de relacionamento social, dificuldades de aprendizado e imaturidade emocional.

\section{O PAI COMO FATOR DE SEGURANÇA EAPOIO}

Uma forma de o pai intervir indiretamente na relação mãe-bebê é através da relação conjugal e do apoio que este oferece a sua esposa. Quando esta relação é satisfatória, é criado um suporte emocional para mãe facilitando a formaçăo de uma relação segura e estimulante desta com o bebê (Rohde, 1991). Apesar de a maioria dos pais não estarem presentes no local do nascimento de seus(as) filhos (as), são exatamente estes que mais expressam a percepção de segurança e apoio que podem transmitir a mulher neste momento.

Foi ruim, fiquei nervoso, queria estar com minha mulher. Acho que o marido estando do lado na hora do parto dá mais segurança (Pai 20).

Os pais que estiveram presentes no nascimento do(a) filho(a) percebem-se, também, como instrumentos de apoio à mulher como relato de alguns:

Eu estava na sala de parto tirando fotos. ... minha esposa queria que eu assistisse, mas depois eu também comecei a querer, dar força para minha esposa e vero momento do nascimento (Pai 6).

O parto não é somente o fim da gravidez, mas é o começo do exercicio da função de maternidade e paternidade. Após o parto é de extrema importância que o pai, a mãe e o bebê fiquem por alguns instantes sozinhos, seja na sala de parto, seja em uma sala próxima por, pelo menos, uma hora. Neste momento, o pai pode participar também do contato pele a pele com a criança estabelecendo inicio de contato tátil com o filho. Geralmente, a mãe e o pai nunca esquecem essa experiência compartilhada de inicio do processo de apego ao filho (Knuppel ; Drukker, 1996).

\section{CONSIDERAÇÕES FINAIS}

Ao concluir este estudo, vimos que dos 23 pais entrevistados apenas um, cujo parto é custeado pelo SUS, assiste ao nascimento do filho e mesmo assim, esta situação ocorre por acaso, visto que o mesmo encontrava-se acompanhando a mulher durante seu trabalho de parto; apenas um dos pais cujo nascimento do filho é custeado por outra fonte que năo o SUS, não assiste o nascimento do filho, em atendimento à solicitação de sua mulher. Portanto, a grande maioria dos pais estava longe do local onde seus(as) filhos(as) nasceram (em casa, no corredor do hospital, na sala de espera do hospital, do lado de fora do hospital fumando, no trabalho) e apenas sete estiveram presentes no nascimento. 
Os motivos referidos para ausência do local do nascimento do(a) filho(a) foram: a restrição da entrada de familiar pela instituição ou por médicos e o desconhecimento do parto iminente, visto sua ausência da instituição durante este periodo. Os motivos referidos para a presença no local do nascimento: dar apoio e segurança à mulher, assistir o parto do filho e não deixar a mulher desacompanhada enquanto aguardava atendimento.

As percepções dos pais quanto a adequação do local de aguardo do nascimento do(a) filho(a) săo de:

$==>$ para os que estiveram presentes, segundo suas próprias palavras "foi maravilhoso, muito bom, o dia mais feliz em minha vida", "uma experiência nova, alegre e diferente, me senti ansioso, nervoso", "foi legal, uma experiência impar, acho que o pai tem que assistir", "foi emocionante estar dentro da sala e ser o primeiro a ver o nenê", "Fiquei emocionado e até chorei", "fiquei apavorado, com medo. Foi uma experiência ótima, mais eu não estava muito preparado e na hora me deu vontade de sair correndo do quarto".

==> para os que estiveram ausentes, conforme seus depoimentos "senti que foi ruim, gostaria de estar junto dela", "fiquei vendo TV, tentando me distrair", "me senti angustiado... foram momentos intermináveis", "eu já estava cansado... quando ela entrou tentei descansar", foram momentos de angústia", "fiquei perdido, andava de um lado para outro preocupado... não sei se eu não iria atrapalhar lá dentro...", "fiquei aflito... foi ruim não estar com ela no momento do nascimento de meu filho", "me senti inseguro estando longe de minha esposa. Acho que o marido deve estar ao lado da mulher dando apoio nesta hora, fazendo força junto", "fiquei nervoso", "me senti sozinho e preocupado com minha esposa", "fiquei ansioso... ficar de fora é horrivel", "foi uma surpresa", "foi ruim, fiquei nervoso, queria estar com minha mulher ... dá mais segurança", "me senti impotente", "estava preocupado".

As falas de muitos pais apontam a passividade na exigência do direito à participação no nascimento. This (1987) cita a necessidade de modificar as estruturas hospitalares que se opõem a presença do pai na sala de parto, alegando que, em clinicas particulares os pais não são separados se assim o desejarem. A realidade encontrada, principalmente em hospitais da rede pública, mostra a resistência por parte de profissionais da área da saúde em liberar a participação do pai neste momento. É preciso conscientizar a populaçăo menos informada e auxiliar na promoção de mudanças nas instituições.

Espera-se com este trabalho deixar claro o local onde é encontrado o pai no momento do nascimento do(a) filho(a) e, a partir da divulgação dos resultados da pesquisa haja possibilidade de reflexão das instituições, principalmente as públicas, quanto a adequação de suas condutas relativas a permissão para entrada deste, propiciando melhor desenvolvimento da paternidade $e$ da criança.

Penso que o novo pai deva receber o filho em suas mãos, desde a saida do ventre materno, depositando-o delicadamente sobre o ventre daquela que acaba de trazê-lo ao mundo; que este contato precoce possa trazer os beneficios esperados para criança; que o casal, neste instante único, desenvolva precocemente laços de afeto e de apego com essa criança; que o lugar de espera do pai não seja, como até o momento, na maioria das situaçōes, a ausência do local de nascimento do(a) filho(a).

ABSTRACT: The purpose of this work is to identify the place where the father is at the time his son/ daughter is being born and his perceptions about this place. This study has a qualitative nature and the Minayo's (1996) reference of speech analisys is used. In order to do it, twenty-three fathers whose children have been born within the present year were interviewed. The approach was direct and they were interviewed in public places. We verified that only seven fathers were present at the moment of parturition, and that among them, only one had his wife's delivery assisted by the SUS. The other interviewed fathers were absent from their children's birthplace. The conclusion is that in spite of all the encouragement given to the father by the correspondent bibliography to be present at the moment of his children's birth for a precocious father-baby interaction, reality shows us that, especially in hospitals where onecan be assisted by the SUS, men are excluded from this very important moment.

KEYWORDS: father, waiting place, father's perceptions, repercussions, SUS. 
RESUMEN: Este trabajo fue escrito con la intención de identificar el local donde los padres se encuentran en el momento del nacimiento de sus hijos(as) y sus percepciones al respecto del lugar. Se trata de un estudio de naturaleza cualitativa, que utiliza el referencial de Minayo (1996) de análisis del discurso. Para este trabajo fueron entrevistados 23 padres de hijos(as) nacidos hace menos de un año. Ellos fueron abordados directamente en lugares públicos. Verificamos que solo siete padres estuvieron presentes en el momento del nacimiento de sus hijos(as), siendo que, solamente uno de ellos nació com parto atendido por el SUS. Los demás entrevistados estuvieron ausentes del local de nacimiento del hijo(a). Se concluye que, por más que la bibliografia incentive su presencia en el momento del nacimiento para una mejor integración entre el padre y el bebé, en la práctica encontramos una realidad diferente, principalmente en los hospitales que atienden por el SUS, donde los hombres son excluidos de este momento tan importante.

PALAVRAS LLAVE: Padre, lugar de espera, percepciones del padre, repercusiones, SUS

\section{REFERENCIALBIBLIOGRÁFICO}

COSTA, Kley P. : KATZ, Jildo e Colaboradores. Dinâmica das relaçōes conjugais. Porto Alegre: Artes Médicas, 1992.

ESPIRITO SANTO, Lilian Córdova do. Sentimentos e percepçōes do pai quanto a sua presença na sala de partos. Revista Gaúcha de Enfermagem, Porto Alegre, v. 14, n.1, p. 34-39, jan. 1993.

KNUPPEL, Robert A .; DRUKKER, Joan E. Alto Risco em Obstetricia: Um Enfoque Multidisciplinar. 2. ed. Porto Alegre: Artes Médicas, 1996.

MELLO, Fábio. Pai é para sempre. Revista Crescer, Sảo Paulo, mar. 1999.

MYNAIO, Maria Cecilia de Souza. O desafio do conhecimento - Pesquisa qualitativa em saúde. 4. ed. Sāo Paulo - Rio de Janeiro: Hucitec - Abrasco, 1996.

MYNAIO, Maria Cecilia de Souza. Pesquisa Social - Teoria, método e criatividade. 7. ed. Rio de Janeiro: Vozes, 1997.

ORGANIZAÇĀO MUNDIAL DA SAÚDE. Tecnologia apropriada para o nascimento e parto. Trad. Sonia N. Hotimsky. Lancet, n. 24, p. $436-37,1985$.

POLIT, Denise F. ; HUNGLER, Bernadette P. Fundamentos de Pesquisa em Enfermagem. 3. ed. Porto Alegre: Artes Médicas, 1995.

PRADO, Luiz Carlos. O pai ausente. Publicaçāo do CEAPIA - Centro de Estudos, Atendimento e Pesquisa da Infância e Adolescência. Ano II, n.2, nov. 1989.

RAPHAEL-LEFF, Joan. Gravidez - A história interior. São Paulo: Artes Médicas, 1997.

RODHE, Luis Augusto e Colaboradores. A função paterna no desenvolvimento do bebê. Revista Psiquiátrica, Rio Grande do Sul, v. 13, n. 3, p. 127-35, set./dez. 1991.

SCHNEIDER, Jacó Fernando e Colaboradores. A paternidade na perspectiva de um grupo de pais. Revista Gaúcha de Enfermagem, Porto Alegre, v. 18, n.2, p. 113-122, jul. 1997.

THIS, Bernard. O pai: Ato de nascimento. Porto Alegre: Artes Médicas, 1987.

ZIEGEL, Erna E. ; CRANLEY, Mecca S.. Enfermagem Obstétrica. 8, ed. Rio de Janeiro: Guanabara, 1985. 